\title{
Correlational investigation of manufacturing technology and environmental impact in an agricultural machinery industry
}

\author{
Hoose A.* and Kripka M. \\ Department of Engineering, University of Passo Fundo, Passo Fundo, Brazil \\ Received: 30/04/2021, Accepted: 23/05/2021, Available online: 26/05/2021 \\ *to whom all correspondence should be addressed: e-mail: andersonhoose@upf.br \\ https://doi.org/10.30955/gnj.003691
}

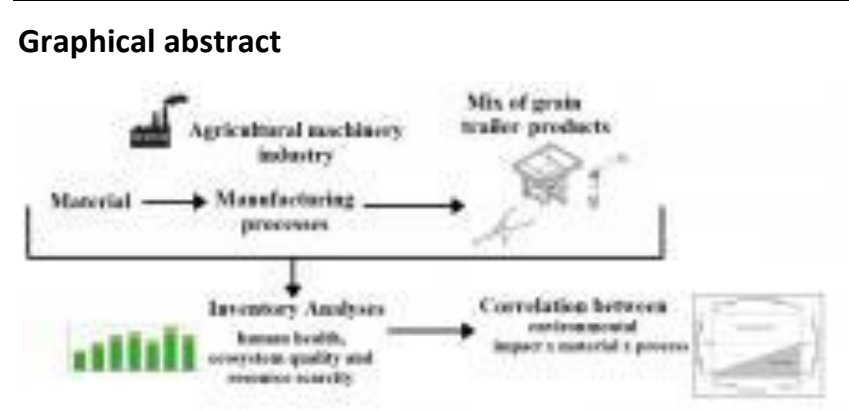

\begin{abstract}
There is a relation between the environmental impacts to the high emissions in the environment and the natural resources depletion, which can be measured with the useful life of the products, affected by the manufacturing technologies and the sustainable development. In this background, the present article aims to evaluate the environmental impact generated by the manufacturing technology in an agricultural machinery industry, in the grain trailer production, regarding the lifecycle from the cradle to the gate. The study consists in a practical adoption in the industry, where the product and the production flow were identified, the inventory analysis was performed and later the environmental impact was evaluated, considering three categories of ending damage (endpoint): human health, ecosystem and the scarcity of resources, in addition to twenty-two environmental impact categories (midpoint). There is a strong correlation among the use of carbon steel and stainless, the laser machining process and the environmental impact, where the human health damage category is the most impacted in the carbon dioxide element, gas associated to the greenhouse effect. The consumerism of the natural resources for the energy generation is the category which most affected in the scarcity of the fossil resources.
\end{abstract}

Keywords: Sustainability, human health, lifecycle, agribusiness, linear correlation.

\section{Introduction}

The environmental impacts that cover the lifecycle of the products are connected to the high emissions of elements and the natural resources depletion, which can vary in its environmental magnitude (RIVM, 2017). Numerous publications in the field mention the human health concerning, the global warming and the natural resources scarcity (Shanbag and Manjare, 2020). Plenty of this is resulting of the development of manufacturing technologies which provided a revolution in different areas of modern society and the sustainable development, where there is the manufacturing, the infrastructure and the technological advances (Akinaga, 2019; Filho et al., 2019). From the manufacturing point of view, the competition is increasing and there is the constant search for improving the efficiency and keeping the products production with a high-level quality (Fatrias et al., 2018). The estimation is that the agricultural machinery industry increases on average $5.8 \%$ year in Brazil, being the agribusiness representation around $22.54 \%$ of the GDP (Arias et al., 2017; Butov, 2016).

Another aspect that covers the use of manufacturing technologies goes to the sustainable development, where it aims to significantly increase the participation of the industry in the employment and in the gross domestic product, update and refresh the industry (United Nations, 2015). There are also other concerns, regarding keeping the activity in the workplaces, due to the seasonality period, because $20.1 \%$ of the workforce in the country works in the many agribusiness segments (Castro et al., 2020). To avoid the impact in the sales, there is the manufacturing of many products models, aiming to soften the assembly line production. Thus, with a bigger market and more varieties of products, little is known about the impact of the use of manufacturing technology in the environment.

As examples of the studies aimed to the environmental impacts are the analysis of the refrigerant liquid lifecycle used in the cryogenic and conventional machining, where the factors of the environmental impact were defined as greenhouse effect gas emission, the residue flows and the water consumption. It was attained a broad advantage in most sustainable aspects analyzed in relation to the cryogenic machining (Lu et al., 2018). In the pulp and paper industry, the sustainability in the manufacturing of paper towels was compared, considering two different manufacturing lines, and it was concluded that the paper 
towels that are manufactured in the most advanced line, are more sustainable compared to the oldest one (Ingwersen et al., 2016).

Another study identified the sustainability changing when there was a process alteration of a set of pieces, using a part consolidation with use of the additive manufacturing. It was noticed the reduction of the energy consumption, reduction in the environmental impact during the manufacturing time, but it was seen a bigger toxicity for the human health (Yang et al., 2017). Yet, the products manufactured by additive manufacturing may be more sustainable than the ones manufactured by conventional manufacturing, since the components have a complex geometry (Hapuwatte et al., 2016).

In the industry of this study, the Production Planning and Control department (PPC), along with the Manufacturing Engineering act in the improving and management of the production. Studies show the lead-time for the manufacturing of the products is one of the most important parameters used by the PPC (Gyulai et al., 2017). There is also manufacturing capacity operation, inventory reduction and delivery time (Reschke and Schuh, 2017).The authors do not know the environmental impact parameters generated by the manufacturing technology, material or processes. Such factor might be important for the sustainable development, update and refresh the industry.

This article has as a goal to evaluate what is the environmental impact generated by the manufacturing technology in an agricultural machinery industry, in the production line of grain trailers, considering the lifecycle analyses from the cradle at the gate. The article is in the following way: first, the studies about the sustainability and sustainable development. Secondly, the methodo-logical procedure of the study. Thirdly, the results and then the results discussion. Finally, the final considerations with the suggestions for upcoming paper works.

\section{Materials and methods}

The methodology is the Life Cycle Analyses (LCA): define scope and goal, overall inventory analysis, impact assessment, and interpretation (ABNT NBR ISO 14040, 2014). To reach the goal of the paperwork, it was necessary to identify the problem, the product settings, and the production flow, analyze the inventory using SimaPro software, and later assess the environmental impact. The linear correlation between materials, processes and environmental impact was assessed by Pearson's linear correlation coefficient (Larson and Faber, 2015).

\subsection{Identification of the problem}

The studied industry is one of the biggest farming machinery manufacturer; it is in the South of Brazil, in Rio Grande do Sul State. Its foundation was in 1960 and it covers a manufacturing area of 100,000 meters square, employing 1,200 employees. They manufacture products for fertilizer distribution, soil preparation and cleaning, spraying, supplying and transportation of grains, planting and harvest. The grain trailer is manufactured during all over the year is, with $10,500,12,000$ and 15,000 liters capacity. This agricultural implement is used to transport grains or fertilizer. The company does not evaluate the environmental impacts resulted from the products manufacturing.

\subsection{Scope definition}

Altogether, there are 5 implements settings for the grains transportation, which are manufactured and sold along the year. The PPC informed the current demand is 3 machines per day, 2 with multi-purpose tube and 1 mach-ine with mechanical tube. The implement settings are:

- 10.5DcTmul represents the agricultural machine with 10,500 liters transport capacity of grains and fertilizers. There is a carbon steel storage and multipurpose discharge pipe.

- 10.5DiTmul represents the agricultural machine with 10,500 liters transport capacity of grains and fertilizers. There is a stainless steel storage and multipurpose discharge pipe.

- 12.0DiTmeci represents the agricultural machine with 12,000 liters transport capacity of grains and fertilizers. There is a stainless steel storage and multipurpose discharge pipe.

- 15.0DcTmec represents the agricultural machine with 15,000 liters transport capacity of grains and fertilizers. There is the carbon steel storage and multipurpose discharge pipe.

- 15.0DiTmul represents the agricultural machine with 15,000 liters capacity of grains and fertilizers. There is stainless steel storage and multipurpose discharge pipe.

The study is from the raw material used in the manufacturing, to the end in the assembly line.

\subsection{Inventory analyses}

This step represents the primary data collection, along with the manufacturing process of the grain trailers. The lifecycle inventory has the goal to identify and quantify the environmental interventions related to the systems, putting the results in an environmental inlet and outlet list (Roy et al., 2019). The data was collected through a product structure list, operation time, manufacturing process flow observation and non-structured interview with the industrial manager, and PPC, welding and painting supervisors.

The SimaPro database version 9.0.0.49 was another data source, where the library (database) was used: Ecoinvent 3, USLCI (the United States life cycle data inventory), and Industry data 2.0. These SimaPro libraries provided the data referred to the raw products and production processes, used in the manufacturing processes. The data updating covers from April 2015 to November 2018.

The raw products values to manufacture 1 square meter of the product (grain trailer) are in Table 1 . The processes are in Table 2, where: 
Table 1. Material used by square meter of the product

\begin{tabular}{ccccccc}
\hline Materials & jun. & 10.5DcTmul & 10.5DiTmul & 12.0DiTmeci & 15.0DcTmec & 15.0DiTmul \\
\hline Steel, engineering steel & $\mathrm{kg}$ & 103,2165 & 69,7484 & 55,8541 & 106,2000 & 72,9938 \\
\hline Steel, stainless 304 & $\mathrm{kg}$ & 0,0586 & 25,1762 & 37,8624 & 0,0508 & 34,2421 \\
\hline PVC pipe & $\mathrm{kg}$ & 2,7527 & 2,7527 & 0,0000 & 0,0000 & 2,7527 \\
\hline Epoxy resin, liquid & $\mathrm{kg}$ & 0,0089 & 0,1503 & 0,1503 & 0,0089 & 0,1527 \\
\hline
\end{tabular}

Table 2. Manufacturing processes used by square meter of the product

\begin{tabular}{ccccccc}
\hline Manufacturing processes & un. & 10.5DcTmul & 10.5DiTmul & 12.0DiTmeci & 15.0DcTmec & 15.0DiTmul \\
\hline Painting, electrocoating & $\mathrm{m}^{2}$ & 0,7064 & 0,3102 & 0,1880 & 0,7539 & 0,3212 \\
\hline Laser machining, metal, with CO2 & $\mathrm{hr}$ & 0,0905 & 0,1100 & 0,1106 & 0,1073 & 0,1175 \\
\hline Welding, gas, steel & $\mathrm{m}$ & 8,2091 & 7,6495 & 5,2768 & 8,6174 & 7,5135 \\
\hline Welding, gas, stainless & $\mathrm{m}$ & 0,0000 & 1,0963 & 1,4728 & 0,0000 & 1,1454 \\
\hline Zinc coat, pieces & $\mathrm{m}^{2}$ & 0,1821 & 0,1821 & 0,0281 & 0,1342 & 0,1821 \\
\hline
\end{tabular}

Table 3. Alternatives analyzed according to the product mix demand

\begin{tabular}{|c|c|c|c|c|c|c|}
\hline \multirow[b]{2}{*}{ Product mix alternatives } & \multicolumn{6}{|c|}{ Quantity of products } \\
\hline & 10.5DcTmul & 10.5DiTmul & 12.0DiTmeci & 15.0DcTmec & 15.0DiTmul & Total \\
\hline $\mathrm{A} 1$ & 2 & & & 1 & & 3 \\
\hline $\mathrm{A} 2$ & 2 & & 1 & & & 3 \\
\hline $\mathrm{A} 3$ & 1 & & 1 & & 1 & 3 \\
\hline A4 & & 2 & 1 & & & 3 \\
\hline A5 & & 2 & & 1 & & 3 \\
\hline A6 & & & 1 & & 2 & 3 \\
\hline A7 & & & & 1 & 2 & 3 \\
\hline
\end{tabular}

\subsection{Scenario analysis and environmental impact assessment}

The scenario analysis and environmental impact assessment presentation is in 4 levels:

1) Raw product/product square meter scenario;

2)Process/ product square meter scenario;

3) Product scenario;

4) Product mix scenario.

The analysis of these scenarios was performed using the SimaPro software. The impact analysis was performed using the ReCiPe 2016 Endpoint (H) V1.03/World (2010) $\mathrm{H} / \mathrm{H}$ methodology. The choice of such a methodology is justified by SimaPro as being the most commonly used to measure the environmental impact from a moderate point of view.

The scenario analysis corresponds to each assessment level of the life cycle impacts, aiming to obtain adding information to support the results evaluation of the product system life cycle, aiming to a better understanding to its environmental significance (ABNT NBR ISO 14040, 2014).

The impact category indicators may describe an environmental problem (midpoint) or evaluate a damage caused on the protection area or domain (endpoint) covering human health, ecosystem quality and resource scarcity. Both categories are complementary, since midpoint has a stronger relation to the environmental flows and endpoint provides better information about the environmental relevance (RIVM, 2017).

\subsubsection{Raw product scenario analysis}

Initially, there is a scenario analysis with the average of the four raw products used in square meters in the grain trailer manufacturing. The materials were identified in SimaPro. Considering all the materials used: the carbon steel (Steel, engineering steel) represents $74.8 \%$, the stainless steel (Steel, stainless 304) represents $18.3 \%$, the polyvinyl chloride (PVC pipe) $1.5 \%$, and the finishing liquid paint (Epoxy resin liquid) $0.1 \%$.

\subsubsection{Manufacturing process scenario analysis}

The scenario analysis with the square meter processes for the grain trailers manufacturing is the cutting with the laser cutting machines of 6,000 Watts of power, which represent $56.2 \%$ of the material cutting. The welding preparation, the MIG welding and stainless MIG corresponding to $36.1 \%$ and $3.9 \%$ respectively. The painting process with polyester powder (Painting, electrocoating) represents on average $14.6 \%$ and liquid paint $4.9 \%$ of the painting processes and surface preparation. It still has the processor for coating the parts with zinc (zinc coat, pieces).

\subsubsection{Product mix scenario analysis}

The product mix scenario analysis was performed considering an amount of seven alternatives (Table 3). For a better exploitation of the manufacturing capacity, the PPC aims to perform the plant programming on a basis of the product mix, being these seven alternatives used nowadays.

The product mix is at SimaPro software, considering each one of the seven alternatives. After assessing the environmental impact, the linear correlation coefficient between materials, processes, and the environmental impact was determined. This approach is commonly used in the analysis of the correlation between air pollutants 
(Jiang et al., 2016). Linear correlation was also used to correct the difference between the theoretical optical thickness (in $\mathrm{m}$ ) and the apparent optical thickness (in $\mathrm{m}$ ). The destruction of the ozone layer and an increased risk of incidence of skin cancer were observed (Hayashi et al., 2000).

\section{Results and discussion}

\subsection{Environmental impact evaluation by raw product}

The results generated by the SimaPro software, considering the material average to manufacture 1 square meter of each product, carbon steel, stainless steel, PVC and finishing liquid paint, are demonstrated on Figure 1. It presents the environmental impact with a single score, with a breakup in 3 impact categories: human health, ecosystem quality and natural resources. The environmental impact is performed in eco-indicators units, the standard values of the ecological indicator. Thus, the unit $\mathrm{mPt}$ (milli-point), where $1000 \mathrm{mPt}=1 \mathrm{Pt}$. The demonstration of the values is in a single score (weighting factor), where the main goal is to compare the relative differences between products or components. The scale in the $1 \mathrm{Pt}$ value is representative of one millionth of environmental burden year of one European inhabitant (E99, 2000).

Considering the material quantity used in 1 square meter of products, the stainless steel brings a higher global impact, followed by the carbon steel (Figure 1). The stainless steel environmental impact (4.93Pt) is $26.4 \%$ higher than the carbon steel (3.9Pt). Regarding to human health and ecosystem, the carbon steel has a higher impact, however, regarding to resource scarcity, the carbon steel has a higher impact compared to stainless steel, it is $10.3 \%$ above to stainless steel, which is the second material with the biggest impact in this category.

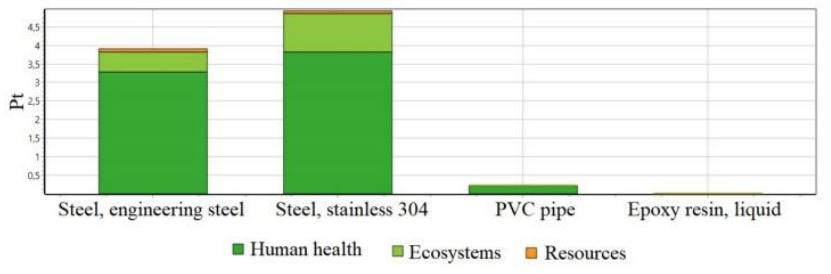

Figure 1. Environmental impact of the materials by single score generated by square meter of the product

The 3 categories (human health, ecosystems and resources) can be divided into 22 categories of impact midpoint, where it is observed that the PVC does not cause impact on ionizing radiation; however, this one is higher in human carcinogenic toxicity, prevailing the biggest quantity substance, the organochloride pollutant, $2,3,7,8$ tetraclorodibenzo-p-dioxina. The stainless steel has a higher impact on water consumption, relating to the water used from rivers, wells and for the use in turbines.

All other impacts on human health, in higher quantity are related to carbon steel in 6 categories: global warming, stratospheric ozone depletion, ionizing radiation, ozone formation, fine particulate matter formation and human non-carcinogenic toxicity. The elements carbon dioxide, methane, dinitrogen monoxide, carbon-14, cesium-137, radon-222, nitrogen oxide, substances released into the air, sulfur dioxide particles $<2.5 \mu \mathrm{m}$ and zinc are in larger quantities on these 6 categories.

The ecosystem impact, considering the total amount of material. The stainless steel presents higher impacts on water consumption of the aquatical and terrestrial ecosystem and in the marine eutrophication. The river water use in turbines and the ammonium are the elements that include in higher quantity.

The liquid paint presents a better impact on the eutrophication in fresh water, where phosphate is in higher quantity. The zinc and bisphenol $\mathrm{A}$ are in higher quantity in fresh water ecotoxicity. Zinc in marine ecotoxicity.

Relating to the carbon steel use, 6 categories perform the highest impacts on the ecosystem in 6 categories. The higher quantity elements are carbon dioxide, nitrogen oxide, sulfur dioxide, zinc, arable land occupation and forest occupation.

In terms of mineral resource scarcity, the stainless steel generates the highest impact. The major quantities are the magnesium, nickel and silicon. Moreover, the carbon steel is on second place on this impact, and the substance with the highest quantity is molybdenum.

In terms of fossil resource scarcity, the carbon steel and stainless steel perform the highest impacts on the use of the same resources. The use of these resources are for the energy generation. There are the following quantities, for the carbon steel and stainless steel, respectively: coal, oil and natural gas. The steel industry is responsible for almost $9 \%$ of the anthropic energy of the world, becoming urgent to reduce the total use of the energy, due to the enormous pressure on the energy consumption and carbon dioxide emission. As a solution, there is the consideration that the adjustment of the capacity of the steel industry devices, to reduce the overage gas may improve the energetic efficiency of the steel production process, indirectly reducing the energy consumption (Wang et al., 2013).

\subsection{Environmental impact evaluation by process}

Figure 2 represents the comparison among square meter manufacturing processes. The laser machining $(233 \mathrm{mPt})$ generates the highest environmental impact. In the industry, the stainless steel demands more hours in the laser machine cutting process, presenting a more superior environmental impact, compared to the other processes, considering the single measures.

The cutting using the laser machining is $146.8 \%$ higher than the second process with a bigger impact, the welding MIG (94.4mPt). To enhance the environmental impact coverage visualization, the 22-midpoint impact categories were listed, broke up in 3 categories: human health, ecosystems and resources. 


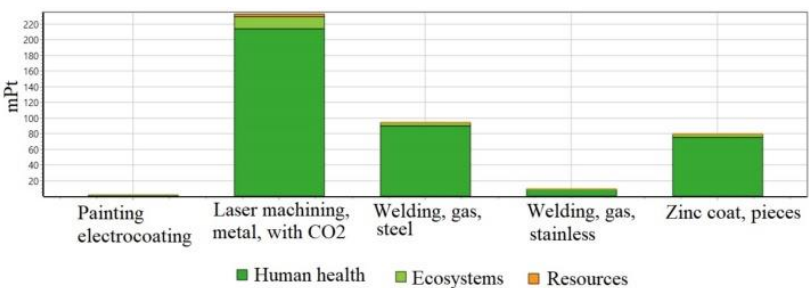

Figure 2. Process environmental impact on manufacturing by single score, generated by product square meter

Regarding to the human health impact, the laser-machining cutting affects in 6 categories. Carbon dioxide, dinitrogen monoxide, radon-222, nitrogen oxide, sulfur dioxide and water consumption in turbines is the element which determines in bigger quantity relating to the impact categories.

The pieces galvanizing process causes a higher impact in the non-carcinogenic toxicity, with a bigger quantity in barium element. The MIG welding process causes more impact in carcinogenic toxicity, with a bigger quantity in chrome element.

The 12 impact categories regarding the ecosystems. In 11 categories, the laser machining process has a bigger impact and in 1 category the pieces galvanizing presents a higher impact.

Laser machining has a higher impact in 11 categories, where the carbon dioxide, nitrogen oxide, sulfur dioxide, phosphate, nitrate, copper, zinc, intensive forest use and turbine use consist of bigger quantities in the impact categories. The pieces galvanizing process causes more influence on the terrestrial ecotoxicity, where the zinc is the most used element.

Regarding the resources scarcity influence, the pieces galvanizing causes a bigger impact on mineral resources scarcity, with a bigger quantity of lead. On this category, the laser equipment is the one that causes a bigger impact on iron element. The laser machining impacts more on fossil resources scarcity, on the elements: natural gas, coal and oil.

\subsection{Environmental impact evaluation by product}

The comparison result, regarding the used materials on the five products (see Figure 3).

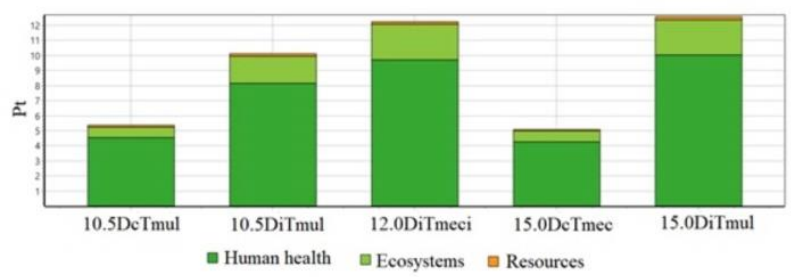

Figure 3. Environmental impacts generated by square meter of the product, regarding materials

The comparison result, regarding the used processes on the products, is on Figure 4.

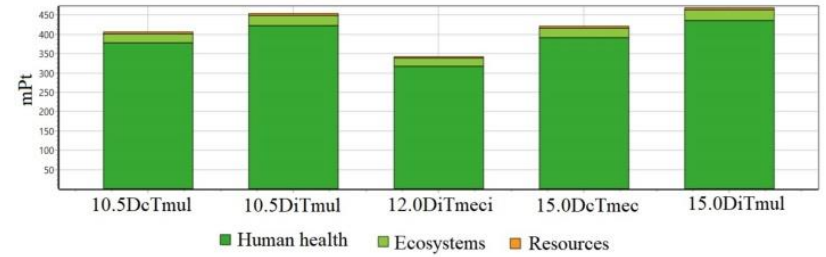

Figure 4. Environmental impacts caused by product square meter, regarding the processes

Regarding the material, the stainless steel warehouse products cause a higher environmental impact compared with the carbon steel warehouse (10.5DiTmul - 10,1Pt, 12.0DiTmeci-12,3Pt e 15.0DiTmul-12,6Pt) (see Figure 3). Comparing the manufacturing processes, the highest environmental impact is generated by the stainless steel warehouse products, and that use the multipurpose pipe (10.5DiTmul - 454mPt, and 15.0DiTmul - 469mPt). These products perform more elevated laser machining time, more welding MIG quantity and pieces galvanizing (see Figure 4). The environmental impact of the material is superior to the processes. For instance, the environmental impact of $10.5 \mathrm{DcTmul}$ product is $5.35 \mathrm{Pt}$ and of the process is $0.406 \mathrm{Pt}(406 \mathrm{mPt})$.

Figure 5 presents the environmental impact result with single score, adding the material and processes.

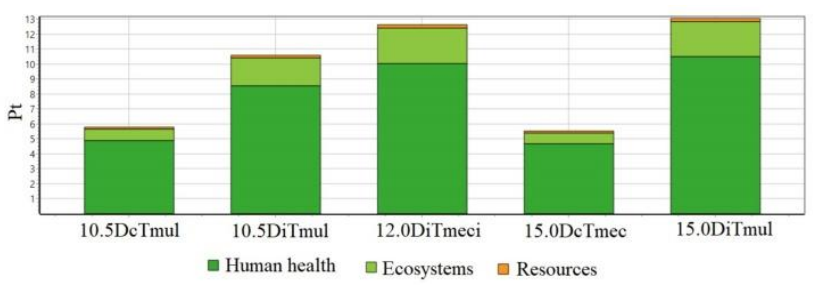

Figure 5. Environmental impacts caused by product, considering material and processes

\subsection{Environmental impact evaluation by product mix}

Based on the mix product demand, Figure 6 performs the global environmental impact, based on mix demand. The product mix is composed by a current demand of 3 machines per day, being 2 machines with multipurpose pipe and 1 machine with mechanical pipe.

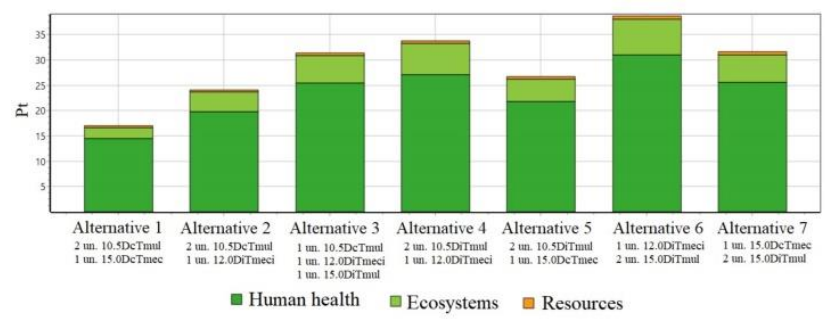

Figure 6. Environmental impacts caused by product mix, considering material and processes

Alternative 1 represents the product mix where the lowest environmental impact was obtained (17Pt - 2 units 10.5DcTmul and 1 unit 15.0DcTmec). These products have the carbon steel product warehouse in common. Whereas alternative 6 represents the product mix where both the implement models have the stainless steel warehouse, 
presenting a higher environmental impact $(38,7 \mathrm{Pt}-1$ unit 12.0DiTmeci and 2 units 15.0DiTmul).

The 22 impact categories (midpoints) associated to the material used in the products and the production process to manufacture the products are on Table 4. Each impact category has the material and the process that causes the highest environmental impact marked. At the bottom, there is the amount of times the material or process caused the highest impact on the category, and finally the position ranking related to the biggest score in the eco-indicators.

Note that the carbon steel material is superior in the environmental impact in 13 categories, and the stainless steel in 5 categories. However, the stainless steel is the $1^{\text {st }}$ place in environmental impact generation, and the carbon steel is the $2^{\text {nd }}$. The importance of these two materials, as much in the products using (a 93.1\% average), as in the environmental impact, taking the $1^{\text {st }}$ and $2^{\text {nd }}$ place and together are the ones that most affect the 18 categories.

Regarding the manufacturing processes, the laser machining is the one that most impacts in the environment in the 18 categories, being the first place in generating the highest environmental impact.

Relating to the elements and substances identified more frequently, there is:

Table 4. View of the highest material and processes impacts on the manufacturing

\begin{tabular}{|c|c|c|c|c|c|c|c|c|c|}
\hline \multirow[b]{2}{*}{$\begin{array}{l}\text { Impact } \\
\text { Categories } \\
\text { (Midpoints) }\end{array}$} & \multicolumn{4}{|c|}{ Materials used in products } & \multicolumn{5}{|c|}{ Production process to manufacture the products } \\
\hline & $\begin{array}{c}\text { Steel, } \\
\text { engineer- } \\
\text { ing steel }\end{array}$ & $\begin{array}{c}\text { Steel, } \\
\text { stainless } \\
304\end{array}$ & $\begin{array}{l}\text { PVC } \\
\text { pipe }\end{array}$ & $\begin{array}{l}\text { Epoxy } \\
\text { resin, } \\
\text { liquid }\end{array}$ & $\begin{array}{l}\text { Painting, } \\
\text { electro- } \\
\text { coating }\end{array}$ & $\begin{array}{c}\text { Laser } \\
\text { machining, } \\
\text { metal, with } \\
\mathrm{CO}_{2} \\
\end{array}$ & $\begin{array}{l}\text { Welding, } \\
\text { gas, steel }\end{array}$ & $\begin{array}{l}\text { Welding, } \\
\text { gas, } \\
\text { stainless }\end{array}$ & $\begin{array}{l}\text { Zinc } \\
\text { coat, } \\
\text { pieces }\end{array}$ \\
\hline \multicolumn{10}{|l|}{ Human health } \\
\hline $\begin{array}{l}\text { Global warming, } \\
\text { Human health }\end{array}$ & $x$ & & & & & $x$ & & & \\
\hline $\begin{array}{c}\text { Stratospheric } \\
\text { ozone depletion }\end{array}$ & $\mathrm{x}$ & & & & & $x$ & & & \\
\hline Ionizing radiation & $x$ & & & & & $x$ & & & \\
\hline $\begin{array}{c}\text { Ozone } \\
\text { formation, } \\
\text { Human health }\end{array}$ & $x$ & & & & & $x$ & & & \\
\hline $\begin{array}{l}\text { Fine particulate } \\
\text { matter formation }\end{array}$ & $x$ & & & & & $x$ & & & \\
\hline $\begin{array}{c}\text { Human } \\
\text { carcinogenic } \\
\text { toxicity }\end{array}$ & & & $x$ & & & & $x$ & & \\
\hline $\begin{array}{l}\text { Human non- } \\
\text { carcinogenic } \\
\text { toxicity } \\
\end{array}$ & $x$ & & & & & & & & $x$ \\
\hline $\begin{array}{c}\text { Water } \\
\text { consumption, } \\
\text { Human health }\end{array}$ & & $x$ & & & & $x$ & & & \\
\hline \multicolumn{10}{|l|}{ Ecosystems } \\
\hline $\begin{array}{c}\text { Global warming, } \\
\text { Terrestrial } \\
\text { ecosystems } \\
\end{array}$ & $x$ & & & & & $x$ & & & \\
\hline $\begin{array}{l}\text { Global warming, } \\
\text { Freshwater } \\
\text { ecosystems } \\
\end{array}$ & $x$ & & & & & $x$ & & & \\
\hline $\begin{array}{c}\text { Ozone } \\
\text { formation, } \\
\text { Terrestrial } \\
\text { ecosystems } \\
\end{array}$ & $x$ & & & & & $x$ & & & \\
\hline $\begin{array}{c}\text { Terrestrial } \\
\text { acidification }\end{array}$ & $x$ & & & & & $x$ & & & \\
\hline $\begin{array}{c}\text { Freshwater } \\
\text { eutrophication }\end{array}$ & & & & $x$ & & $x$ & & & \\
\hline $\begin{array}{c}\text { Marine } \\
\text { eutrophication }\end{array}$ & & $x$ & & & & $x$ & & & \\
\hline $\begin{array}{l}\text { Terrestrial } \\
\text { ecotoxicity }\end{array}$ & $x$ & & & & & & & & $x$ \\
\hline
\end{tabular}




\begin{tabular}{|c|c|c|c|c|c|c|c|c|c|}
\hline $\begin{array}{l}\text { Freshwater } \\
\text { ecotoxicity }\end{array}$ & & & & $x$ & & $x$ & & & \\
\hline $\begin{array}{c}\text { Marine } \\
\text { ecotoxicity }\end{array}$ & & & & $x$ & & $x$ & & & \\
\hline Land use & $x$ & & & & & $x$ & & & \\
\hline $\begin{array}{c}\text { Water } \\
\text { consumption, } \\
\text { Terrestrial } \\
\text { ecosystem }\end{array}$ & & $x$ & & & & $x$ & & & \\
\hline $\begin{array}{c}\text { Water } \\
\text { consumption, } \\
\text { Aquatic } \\
\text { ecosystems }\end{array}$ & & $x$ & & & & $x$ & & & \\
\hline \multicolumn{10}{|l|}{ Resources } \\
\hline $\begin{array}{l}\text { Mineral resource } \\
\text { scarcity }\end{array}$ & & $x$ & & & & & & & $\mathrm{x}$ \\
\hline $\begin{array}{c}\text { Fossil resource } \\
\text { scarcity }\end{array}$ & $x$ & & & & & $x$ & & & \\
\hline Total & 13 & 5 & 1 & 3 & 0 & 18 & 1 & 0 & 3 \\
\hline $\begin{array}{c}\text { Highest total } \\
\text { impact (ranking) }\end{array}$ & $2^{\circ}$ & $1^{\circ}$ & $3^{\circ}$ & $4^{\circ}$ & $5^{\circ}$ & $1^{\circ}$ & $3^{\circ}$ & $4^{\circ}$ & $2^{\circ}$ \\
\hline
\end{tabular}

a) Carbon dioxide: it was found 6 times in more quantity, contributing to the global warming (human health), terrestrial and freshwater global warming ecosystems. This element is repeatedly on the same categories as much in the material, as in the processes. The steel production and the material cutting (carbon steel and laser machining) contribute to the global warming, need electric power in its productive process. The carbon dioxide is released during the electrical power production, affecting the global warming (Shanbag and Manjare, 2020);

b) Turbines water use: it was found 6 times in more quantity, contributing to the water consumption (human health) and the terrestrial and freshwater water consumption. This element repeated in the same categories as much in the processes as in material. The turbine water use is due to the energy generation for the material production and for the cutting process (found in more quantity for the stainless steel and laser machining). A study identified that for the tire production, the energy generation is what increases the pollution problems, in a superior way to the processes used in production (Shanbag and Manjare, 2020);

c) Zinc was the element found 5 times in more quantity, contributing to the non-carcinogenic toxicity (human health), in the terrestrial eco toxicity, in sea and fresh water (ecosystems);

d) The oil, natural gas and coal: they are in the fossil resources scarcity, not only for the material, but also for the processes. The coal is used for the electricity production, leading to energy sources depletion (Shanbag and Manjare, 2020);

e) Particles $<2.5 \mu \mathrm{m}$ and sulfur dioxide: they are in the fine particles formation category (human health). There are many published studies on the human health effects due to fine particles, among them the respiratory effects (Shanbag and Manjare, 2020). The sulfur dioxide also affects the terrestrial acidification, along with the nitrogen oxides that affect the ozone formation. The rainwater acidity increase occurs mainly due to the sulfur and nitrogen oxide concentration in the atmosphere, being the sulfur dioxide the main responsible (Personal and Archive, 2019).

Regarding the product mix, the alternative 1 product mix generates the lowest environmental impact, while the alternative 6-product mix generates the highest environmental impact. To justify the obtained values from the 7 alternatives, Figure 7 follows, and demonstrates the correlation among the material use in each of the alternatives, considering the carbon plate $(\mathrm{kg})$ and stainless plate $(\mathrm{kg})$, the laser machining hours and the single score environmental impact indicator (Pt). The variation coefficient may vary from -1 to 1 , it means a strong positive linear correlation, $r$ is close to 1 , while in a strong negative linear correlation, $r$ is close to -1 (Larson and Faber, 2015). For each one of the alternatives, the PVC material has the same quantity (in each product mix there are 2 multipurpose discharge pipes). Thus, the environmental impact for all the alternatives regarding this material is the same.

There is a Strong linear correlation negative between the use of the materials: carbon steel and stainless steel ( $r=$ $-0,95)$. The greater is the carbon steel quantity in the products, smaller is the environmental impact $(r=-0,92)$, also, smaller is the stainless steel quantity. There is a Strong linear correlation between the stainless steel to the environmental impact $(r=0,99)$. The greater is the stainless steel quantity, bigger is the environmental impact, it happens a smaller use of the carbon steel material.

Regarding the laser machining, there is also a strong correlation with the stainless steel use $(r=0,85)$. The laser machining time is bigger for the product mix that uses more 
stainless steel material, incurring a higher environmental impact. The inverse may also be considered, the bigger is the carbon steel use, smaller is the laser machining time needed, resulting a smaller environmental impact.
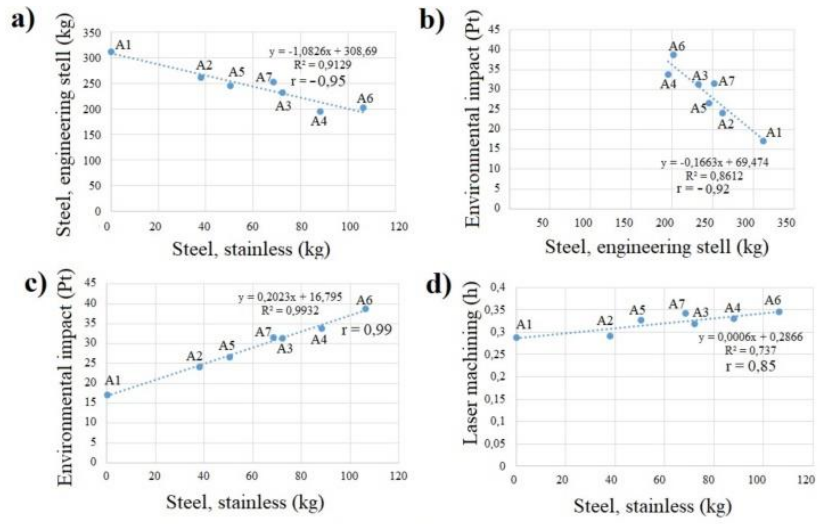

$\mathrm{A} 1, \mathrm{~A} 2, \mathrm{~A} 3, \mathrm{~A} 4, \mathrm{~A} 5, \mathrm{~A} 6, \mathrm{~A} 7=$ Production mix alternatives

Figure 7. Coefficient of Pearson's linear correlation ( $r$ ): a) linear correlation between stainless steel and engineering steel, $b$ ) linear correlation between engineering steel and environmental impact, c) linear correlation between stainless steel and environmental impact, d) linear correlation between stainless steel and laser machine hours

Figure 8 illustrates the environmental impact behavior related to the material used and the laser machining time.

As far as the carbon steel usage increases, the laser machining time decreases, and there is a higher environmental impact. The values indicated on Figure 8 , correspond to the product mix used and evaluated in the study. It will be necessary 0.288 hours of laser machining, using a product mix composed by $99.9 \%$ of carbon steel and $0.1 \%$ of stainless steel, resulting in an environmental impact of $17.033 \mathrm{Pt}$. For the maximum using of the stainless steel in the product mix, 34.5\%, 0.346 laser-machining hours is needed, and results in an environmental impact of 38.696 Pt.

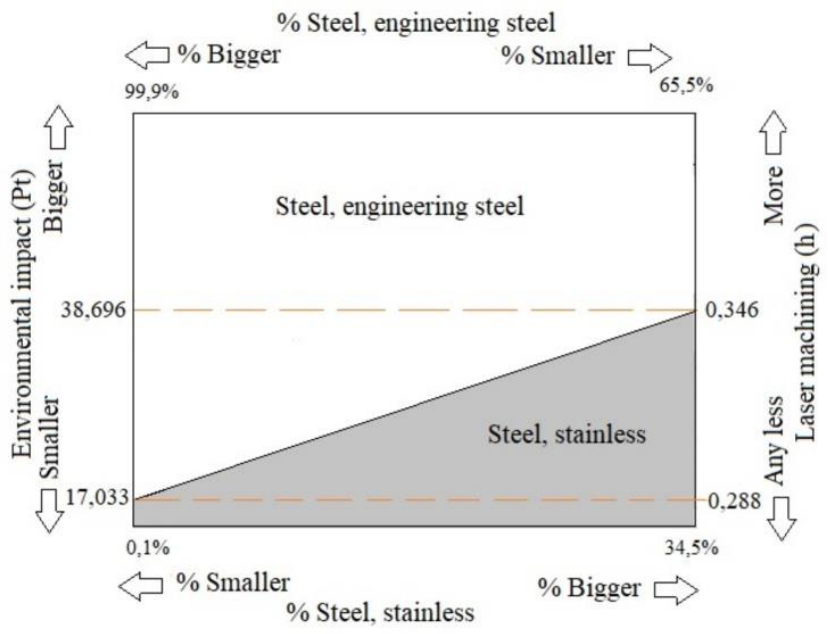

Figure 8. Relation among environmental impact $\mathrm{x}$ material $\mathrm{x}$ process

\section{Conclusions}

The motivation for the study accomplishment is due to the advances in the manufacturing processes and industry materials, where the most used materials are identified to the products manufacturing, being the carbon steel and the stainless steel, including the manufacturing processes, among them, the laser machining. It is possible to evaluate the environmental impact generated by the manufacturing technology, with a strong correlation among the carbon steel, stainless steel materials the laser machining process and the environmental impact.

The raw products and the manufacturing processes analyses were performed, where there was the finding that the raw product in stainless steel promotes a higher environmental impact compared to the carbon steel, PVC and liquid paint. The laser machining process generates higher environmental impacts compared to the processes of polyester powder painting, MIG welding, MIG stainless welding and pieces galvanizing. The human health final damage is the most impacted in carbon dioxide element, gas associated to the greenhouse effect. The natural resources consumption for the energy generation is the element that most affected the fossil resources scarcity.

As a recommendation for the forthcoming paperwork, continuing the study is a suggestion, also considering from the cradle to the grave lifecycle, mainly the materials used in the products recycling, such as the stainless steel and carbon steel elements. Despite the study involves a specific place, there is the understanding that the methodology used may be extended to the industries located in other areas and from other countries.

\section{Acknowledgements}

The authors acknowledge the agricultural machinery industry partners for support.

\section{References}

ABNT NBR ISO 14040. (2014), Associação Brasileira de Normas Técnicas ISO 14040: Gestão ambiental - Avaliação do ciclo de vida - Princípios e estrutura, 22.

Akinaga H. (2019), Nanofabrication technologies for All. Sensors and Materials, 31, 2477-2480.

Arias D., Vieira P.A., Contini E., Farinelli B. and Morris M. (2017), Agriculture productivity growth in Brazil. Agricultue Productivity Growth in Brazil.

Butov A. (2016), Agricultural Machinery Market. (September), 68.

Castro N.R., de Camargo Barros G.S.A., Almeida A.N., Gilio L. and de Paula Morais A.C. (2020), The Brazilian agribusiness labor market: Measurement, characterization and analysis of income differentials. Revista de Economia e Sociologia Rural, 58, 1-20.

Di F., Tri Putri N., Akbar P.G. and Fae F.A. (2018), Optimizing coal blending quality through supplier selection and order allocation: A case of cement industry. MATEC Web of Conferences, 204, 0-5.

E99. (2000), Eco-indicator 99 Manual for Designers: A damage oriented method for Life Cycle Impact Assessment. Ministry of Housing, Spatial Planning and the Environment:1-43.

Filho W.L., Tripathi S.K., Guerra J.B.S.O.D.A., Giné-Garriga R., Lovren V.O. and Willats J. (2019), Using the sustainable development goals towards a better understanding of 
sustainability challenges. International Journal of Sustainable Development and World Ecology, 26, 179-190.

Gyulai D., Pfeiffer A. and Monostori L. (2017), Robust production planning and control for multi-stage systems with flexible final assembly lines. International Journal of Production Research, 55, 3657-3673.

Hapuwatte B., Seevers K.D., Badurdeen F. and Jawahir I.S. (2016), Total life cycle sustainability analysis of additively manufactured products. Procedia CIRP, 48, 376-381.

Hayashi K., Itsubo N. and Inaba A. (2000), Development of damage function for stratospheric ozone layer depletion: A tool towards the improvement of the quality of life cycle impact assessment. International Journal of Life Cycle Assessment, 5, 265-272.

Ingwersen W.W., Ceja M., Weisbrod A.V., Cabezas H., Demeke B., Eason T., Smith R.L., Sengupta D., Zanoli E., Gausman M., et al. (2016), Evaluating consumer product life cycle sustainability with integrated metrics: a paper towel case study. Industrial \& Engineering Chemistry Research, 55, 34333441.

Jiang Z., Zeng Q., Pi H. and Tie B. (2016), Variation in characteristics of air concentrations of $\mathrm{NH}_{3}, \mathrm{NO}_{2}$ and $\mathrm{O}_{3}$ induced by applications of urea in soils of plastic greenhouses in suburban China. Atmospheric Pollution Research, 7, 619-625.

Larson R. and Faber B. (2015), Estatística aplicada. São Paulo: Pearson Education do Brasil.

Lu T., Kudaravalli R. and Georgiou G. (2018), Cryogenic machining through the spindle and tool for improved machining process performance and sustainability: Pt. II, sustainability performance study. Procedia Manufacturing, 21(2017), 273280.

Personal M. and Archive R. (2019), Acid rain is a local environment pollution but global concern acid rain is a local environment pollution but global concern. (91622).

Reschke J. and Schuh G. (2017), Scheduling parameters in production planning and control. IMCIC 2017-8th Int MultiConference Complexity, Informatics Cybernetics Proceedngs 2017, March(1), 57-61.

RIVM. (2017), ReCiPe 2016 v1.1.:201. www.rivm.nl/en

Roy P., Miah M.D. and Zafar M.T. (2019), Environmental impacts of bicycle production in Bangladesh: a cradle-to-grave life cycle assessment approach. SN Applied Sciences, 1, 1-16.

Shanbag A. and Manjare S. (2020), Life cycle assessment of tyre manufacturing process. Journal of Sustainable Development of Energy, Water and Environment Systems, 8, 22-34.

United Nations. (2015), Transforming our world: the 2030 Agenda for Sustainable Development. A/RES/70/1 UN Gen Assem New York.(October):1-35.

Wang P., Jiang Z., Liu Z. and Fu S. (2013), Modeling and optimizing energy utilization of steel production process: a hybrid petri net approach. Advances in Mechanical Engineering, 5, 191963.

Yang S., Talekar T., Sulthan M.A. and Zhao Y.F. (2017), A generic sustainability assessment model towards consolidated parts fabricated by additive manufacturing process. Procedia Manufacturing, 10, 831-844. 